\title{
La construcción de políticas climáticas europeas y su internacionalización: desafíos pasados, actuales y futuros hacia 2020*
}

\author{
María del Pilar Bueno Rubial** \\ Universidad Nacional de Rosario \\ Universidad Nacional de La Plata
}

\begin{abstract}
Sumario: I. Introducción. - II. La construcción doméstica del liderazgo climático europeo: locomotoras y contrapesos. 1. Potencias emisoras y locomotoras de la política climática europea: Alemania, Reino Unido y Francia. 2. Los ralentizadores coyunturales de la UE15: España, Grecia y Portugal. 3. Los nuevos ralentizadores o contrapesos: República Checa, Polonia, Bulgaria y Rumanía.-III. La internacionalización de la política climática europea. - IV Conclusión.
\end{abstract}

Resumen: El artículo propone analizar el proceso de construcción doméstica del liderazgo climático europeo y cómo dichas dinámicas incidieron en la internacionalización de la política climática europea en los foros globales de 2008 a 2014. En tal sentido argumenta que hasta la COP15 la construcción doméstica del liderazgo europeo, a pesar de ser compleja por los actores intervinientes, logró por un lado disolver las diferencias en el interior del bloque y por otro, promover una política climática de liderazgo como Potencia Climática Moral. A partir de 2010 ese liderazgo se vio cuestionado por la interacción de disensos domésticos, más visibles por la crisis en la eurozona; así como por los cambios en el Sistema Internacional.

Palabras claves: Política climática, Unión Europea, liderazgo, internacionalización, sistema internacional.

Abstract: The article aims to analyze the European domestic construction of climate leadership and how these dynamics influenced the internationalization of the European climate policy in global forums 2008-2014. We argue that until COP15 the domestic construction of European leadership, despite being complex due to the actors involved, managed to dissolve the differences within the bloc and promote a climate leadership as a climate Moral Power. Since 2010 this leadership has been questioned by the interaction of domestic dissent more visible by the crisis in the euro zone, as well as by changes in the International System.

Keywords: Climate policy, European Union, leadership, internationalization, international system.

* Artículo recibido el 6 de mayo de 2014 aceptado el 11 de junio de 2014.

** Investigación realiza a través de una Beca Postdoctoral financiada por la Comisión Europea, Europlata 2013-2014 en la Universidad de Deusto. 


\section{Introducción}

El quinto informe del Panel Intergubernamental de Expertos contra el Cambio Climático (IPCC) presentado a pocos días de la celebración de la diecinueveava conferencia de las partes (COP) del Convenio Marco de Naciones Unidas contra el Cambio Climático (CMNUCC) celebrada en la ciudad de Varsovia en noviembre de 2013, es enfático al afirmar que el calentamiento del sistema climático es inequívoco y que muchos de los cambios observados desde la década del cincuenta, no tienen precedentes. Esto implica que la atmósfera y el océano se han calentado, que la nieve y el hielo están disminuyendo, que el nivel del mar está aumentando y que las concentraciones de gases de efecto invernadero (GEIs) hacen lo propio. Del mismo modo, que las tres décadas pasadas han sido más calientes en la superficie terrestre que ninguna otra desde 1850. De hecho, el período 1983-2012 fueron los treinta años más calientes de los últimos 1400 años en el Hemisferio Norte. ${ }^{1}$

Ahora bien, nos ocupa el rol del viejo Continente, Europa, en los avatares climáticos de los últimos años, haciendo especial énfasis en el recorrido perpetrado a partir del denominado primer período de compromisos (1PC) del Protocolo de Kyoto (PK), esto es de 2008 a 2012, y el comienzo del segundo período de compromisos (2PC) que tiene lugar a partir de 2013 y se extenderá hasta 2020. Para dicho momento, la Comunidad Internacional deberá contar con un nuevo acuerdo que reemplace al PK y cuyo contenido y forma aún sigue en debate. El mismo deberá ser delineado, como máximo, en la COP21 a celebrarse en París en 2015, de modo que los países cuenten con el debido espacio temporal para su ratificación, de acuerdo a las lógicas constitucionales de cada Estado.

La trayectoria europea en materia climática es vasta, es posible mencionar algunos aspectos que la caracterizan. Si bien, y tal como lo expresa James Rosenau $^{2}$, la división entre los aspectos internos y externos de un Estado son cada vez más inciertos; sólo a los fines analíticos es útil señalar algunas condiciones que operan más en el terreno doméstico de la Unión Europea (UE) y como motor de su política climática. Mientras tanto, otros, lo hacen en términos más estructurales o externos y algunos parecen ser más imprecisos y por eso empleamos el concepto de Bayless Manning ${ }^{3}$ relativo a las cuestiones intermésticas.

1 IPCC, Cambio Climático 2013. Bases Físicas, disponible en http://www.climate change2013.org/images/report/WG1AR5_ALL_FINAL.pdf, última consulta del 23/04/2014.

2 ROSENAU, J., Along the domestic-foreign frontier. Exploring governance in a turbulent world, Cambridge University Press, 1997.

${ }^{3} \mathrm{El}$ término «interméstico» utilizado por Bayless Manning es un neologismo que refiere a aquellas cuestiones que pueden considerarse simultáneamente de índole doméstica e internacional. MANNING, B., «The Congress, the Executive and Intermestic Affairs: Three Proposals», en Revista Foreign Affairs, vol. 55, n. ${ }^{\circ}$ 2, 1977, pp. 306-324. 
En el plano interméstico, en el cual se desarrolla el clima, que no reconoce fronteras o límites antrópicos, los efectos del cambio climático han sido relativos dependiendo de la zona geográfica a la cual se haga referencia. En el caso de países como Bélgica, Holanda, Luxemburgo, Francia, Alemania e Irlanda, las precipitaciones anuales han aumentado, derivando en inundaciones y aumentos de la temperatura media. Mientras tanto en otras zonas del sur de Europa y del Mediterráneo como España, Portugal, Italia, el sur de Francia, Rumanía y Bulgaria, las precipitaciones han descendido un $40 \%$ respecto a los niveles de $1990^{4}$. A este respecto afirma Daniel Innerarity ${ }^{5}$ que si bien la afectación universal del cambio climático es un motivo para ponerse de acuerdo, las diferentes afectaciones dificultan dicho acuerdo. Refiere a cómo - en algunos casos - el aumento de las precipitaciones puede mejorar las condiciones de cultivo o incluso el atractivo turístico de una zona.

De la misma forma - y en su fase doméstica - la crisis de la eurozona ha forjado una fuerte disminución de la actividad económica, así como ha tenido ondas repercusiones sociales en términos de desempleo, pobreza y precarización del Estado de bienestar. Igualmente, la crisis ha excusado a los gobiernos para refugiarse en recetas conservadoras disminuyendo su capacidad de inversión en energías renovables, cuestión que se ha visto agravada por el alto precio de los combustibles fósiles $-\mathrm{Eu}-$ ropa se ha sostenido como principal importadora mundial de gas natural con una carga de 400 billones de euros en 2012 o 3.1\% del PBI de la UE $-{ }^{6}$. Ahora bien, esta crisis ha conllevado como externalidad positiva, la disminución de las emisiones de GEIs como producto de la ralentización de la actividad económico-productiva ${ }^{7}$. Sería injusto decir que las consecuencias de la crisis han sido equitativas, puesto que algunos países aún experimentan los efectos del paro y los ajustes en la seguridad social, la educación, la ciencia y la tecnología; pilares del bienestar europeo. Por otra parte, los mecanismos de rescate, como el MEDE - Fondo de Rescate Europeo Permanente-, empleados en los casos más críticos, han incrementado el euroescepticismo, fundamentalmente en los países resca-

4 Comisión Europea, 2013/C216/01, disponible en http://eur-lex.europa.eu/LexUriServ/ LexUriServ.do?uri=OJ:C:2013:216:0001:0015:ES:PDF , última consulta del 23/04/2014.

5 INNERARITY, D., «Justicia Climática», en Dilemata, Año 4, n. ${ }^{\circ}$ 9, 2012, pp. 175-191.

${ }^{6}$ Comisión Europea, $\operatorname{COM}(2011)$ 112/4, A Roadmap for moving to a competitive low carbon economy in 2050, disponible en http://ec.europa.eu/commission_2010-2014/ hedegaard/headlines/topics/docs/com_2011_112_en.pdf, última consulta del 23/04/2014.

7 European Environment Agency, Annual European Union greenhouse gas inventory 1990-2011 and inventory report 2013, EEA Technical report, No 8/2013, disponible en http:// www.eea.europa.eu/publications/european-union-greenhouse-gas-inventory-2013, última consulta del 23/04/2014. 
tados y sujetos a una estricta receta de ajuste con una legitimidad social puesta en duda.

Otro elemento de carácter doméstico se vincula a la relación climaenergía. A partir de 2008 la UE decidió fusionar ambos asuntos en un único paquete de medidas. Esto conllevó la consecución del objetivo $20 / 20 / 20$, un compromiso interno y externo de alcanzar un horizonte de reducción de sus emisiones de GEIs en un 20\% para el año 2020, junto con una participación del $20 \%$ de energías renovables en sus matrices energéticas y finalmente un $20 \%$ de mejora en su eficiencia energética. Con este objetivo 20/20/20 se concentraron ambos asuntos en el seno de la Unión, modelo que ha repetido para el nuevo esquema que se ha trazado la Comisión Europea con miras hacia 2030 e incluso hacia 2050 de acuerdo al mapa de ruta.

El último elemento doméstico al que se hace referencia es la propia dinámica de ingreso de nuevos miembros a la UE. La denominada ampliación al Este ha significado nuevos desafíos que incrementan la heterogeneidad de la Unión y jaquean sus capacidades internas y externas, fundamentalmente en un contexto de crisis.

En el plano externo, se mencionan los cambios experimentados en la estructura y dinámica del Sistema Internacional en términos generales y que han impactado en el régimen climático global. Nos referimos a cómo la crisis global convulsionó los principales mercados del mundo llevando a replantearse la arquitectura económica y financiera internacional. Transformaciones reconocidas en el seno del G20 a partir de 2009. Asimismo en 2009, y en el plano climático, la celebración de la COP15 en la ciudad de Copenhague que tenía como principal objetivo trazar el futuro del clima tras la finalización del IPC del PK y con la ruta delineada en COP13 en Bali en 2007. Esta reunión se volvió una bisagra climática connotando que los viejos liderazgos ya no estaban asegurados en un nuevo período de compromisos.

Teniendo en cuenta estos elementos mencionados, nos preguntamos: ¿Cómo se construyó internamente el liderazgo climático europeo y cómo esto repercutió en la internacionalización de la política climática europea en los foros globales de 2008 a 2014?

El proceso de construcción interna del liderazgo climático europeo es complejo puesto que si bien los países con mayores atributos de poder en términos económicos y políticos operarían como cabeza del proceso, tales como Alemania, Gran Bretaña y Francia, existen otros Estados que a pesar de ser «recién llegados» como los países del Este, ejercen influencia en las decisiones como producto de sus propios atributos climáticos. Esto es, por ejemplo, su capacidad de ralentizar el cumplimiento de los objetivos internos e internacionales climáticos de la UE. Del mismo modo, algunos Esta- 
dos de la UE15 que han sido más fuertemente golpeados por la crisis económica internacional, como España, Grecia y Portugal, y si bien no tienen influencia directa por su peso específico o liderazgo en la Unión, al igual que los «recién llegados» ejercen una presión determinante como producto de su condición actual.

La segunda variable de nuestro estudio es la internacionalización de la política climática europea. Partimos entonces de afirmar que existe una subdivisión del período analizado, con un liderazgo externo incuestionado hasta 2009 y otro puesto a debate y aún en ciernes de 2009 a 2014.

El liderazgo del primer período se encuentra ligado a una Europa más reducida numéricamente, próspera económicamente que aprovechó el viento de cola de la construcción de la zona euro. Con un escenario internacional favorable a su liderazgo por ausencia de Estados Unidos en el régimen climático de Kyoto, y una posición de China cómodamente alojada entre el mundo en desarrollo y por ende sin formar parte de los anexos del PK. Así, Europa se autopotenció como Potencia Climática Moral. Esta característica se construye de adentro hacia afuera, no adquiriendo compromisos que no se puedan cumplir y teniendo iniciativas domésticas que sean un faro para otros Estados del régimen. Desde esa postura de modelo, Europa se permitió presionar a otros actores del régimen.

Desde 2009 a 2014, el Sistema Internacional mostró ciertos cambios, como el advenimiento del grupo BASIC y el giro propiciado por Estados Unidos en la era Obama que se venían produciendo en forma paulatina y Europa no logró ajustarse rápidamente.

En consecuencia, afirmamos a manera de hipótesis que hasta la COP15 celebrada en Copenhague la construcción doméstica del liderazgo europeo, a pesar de ser compleja por los actores intervinientes, logró por un lado disolver las diferencias al interior del bloque y por otro, promover una política climática de liderazgo como Potencia Climática Moral. A partir de 2010 ese liderazgo se vio cuestionado como producto de la interacción de los disensos domésticos más visibles por la crisis en la eurozona; así como por los cambios en el Sistema Internacional. Europa no se adaptó rápidamente a ninguno de ellos.

Para dar respuesta al interrogante propuesto dividimos la contribución en dos partes. La primera se centra en la variable construcción doméstica del liderazgo climático europeo y por ende se enfoca en el estudio de los tres grupos de países mencionados a partir de una serie de indicadores. La segunda se orienta hacia la internacionalización de la política climática europea, promoviendo que la conclusión nos permita establecer los desafíos abiertos hacia la consecución de un nuevo acuerdo o documento vinculante que guíe el destino climático global a partir de 2020. 


\section{La construcción doméstica del liderazgo climático europeo: locomotoras y contrapesos}

La decisión de dividir las contribuciones de tres grupos de países al proceso de construcción de la política climática europea durante el primer período de compromisos, responde a que se asume que los esfuerzos, intereses y percepciones al interior del bloque difieren. Si bien no es posible afirmar que los Estados agrupados son homogéneos en sus posturas e intereses, existen algunas condiciones explícitas por las cuales son congregados de este modo.

En el primer caso, el grupo responde a las tres mayores economías de la UE. Se trata de los países más emisores de GEIs en términos totales y quienes, a su vez, se han comprometido en forma diferencial a contribuir con el compromiso solidario europeo de reducir un $8 \%$ sus emisiones de GEIs a valores de 1990 durante el 1PC - no se aplica al caso francés - . Se trata de un grupo que actúa como locomotora económica y política en la UE y consideramos ha asumido dicho rol también en términos climáticos en su sólida vinculación europea con la cuestión energética.

En el segundo caso, son países que ingresaron en la Unión en la década del ochenta, primero Grecia y luego España y Portugal. Son los tres países de la UE15 que se han visto más amenazados por los efectos de la crisis económico-financiera de 2008, con momentos traumáticos de violencia social en el caso griego y de cierta parálisis político-económica en los tres países. En la interacción entre los índices económicos, políticos y climáticos, se trata de Estados que de acuerdo al principio de las responsabilidades comunes pero diferenciadas (CBDR) y al de las capacidades - aplicadas al interior de la Unión-, no sólo no fueron comprometidos a la reducción de sus emisiones durante el primer período, sino que se les permitió incrementarlas. Del mismo modo, se trata de un grupo que durante el 1PC puede haber actuado como un contrapeso, ralentizando el cumplimiento solidario de los compromisos climáticos internacionales a pesar de estar exentos de reducciones.

El tercer grupo, ensambla países incorporados a la Unión entre 2004 y 2013, donde República Checa y Polonia lo hicieron en primer lugar, Bulgaria y Rumanía más recientemente. En términos de sus PBI, hacia 2011 es Polonia quien encabeza la lista, teniendo como contrapunto a Bulgaria como la economía más pequeña. Son países en crecimiento cuyos compromisos de emisión y reducción son variables, pero comparten el hecho de que son los mayores emisores de la UE28 - si dividimos la UE en UE15 y UE28, son los mayores emisores entre los trece ingresos más recientes-, así como Estados intensos en términos de carbono. A pesar de ser países que podrían actuar como «recién llegados» con escasos privilegios en las negociaciones climáticas de la Unión, no es lo mismo el status de Polo- 
nia que el de Bulgaria, posiblemente como producto de la diferencia en sus economías, emisiones y otros aspectos que aquí se relevan.

\section{Potencias emisoras y locomotoras de la política climática europea: Alemania, Reino Unido y Francia}

En términos de indicadores económicos tradicionales, particularmente del producto bruto interno (PBI), el primer grupo está dado por las economías más grandes de la Unión. Donde en 2012, Alemania presentó un PBI de 3150 (1000 millones de euros a precio de mercado y valores PPS); Reino Unido de 2680 y Francia $2770^{8}$. Ahora bien, en términos de PBI per cápita, los números muestran las diferencias que caracterizan a la Unión en su conjunto. Mientras que Luxemburgo ocupa el primer lugar, los tres países mencionados se posicionan entre el noveno y décimo primero lugar, donde Alemania es el primero y Francia el último en el año 2008. Sin embargo, para 2012 Alemania ocupaba el séptimo lugar, seguido por Francia en el décimo y Reino Unido en el décimo primero?.

En el análisis del PBI de los tres países durante el 1PC, surge que su evolución ha mostrado altibajos ligados a la crisis económica y financiera internacional. Justamente el desplome que experimentaron los productos, especialmente en 2009, se debió a este suceso que a partir del segundo cuatrimestre del mismo año comenzó levemente a revertir. Los tres países resistieron importantes disminuciones en sus productos de 2008 a 2009, siendo Alemania y Reino Unido los más damnificados. Alemania evidenció una pérdida del $7 \%$ respecto a los valores de 2008 y Reino Unido cercana al 8\%. En el primer caso, las agencias estadísticas informaron que la caída - entre otros motivos - se había visto pronunciada por la disminución en las exportaciones, por ejemplo de automóviles, componente esencial de la economía germana.

Alemania es la responsable del mayor cúmulo de emisiones de GEIs de la UE28. Entre los años 2008 y 2011 generó entre el 19 y $20 \%$ de las emisiones totales de la UE. Por su parte, Reino Unido es el segundo emisor con un valor que oscila entre 12 y $13 \%$ del total emitido por la UE y en tercer lugar se asienta Francia con valores entre 10 y $11 \%$. Las tres mayores economías eu-

${ }^{8}$ Eurostat, GDP in PPS, datos del 24/02/2014, disponibles en http://epp.eurostat.ec.europa .eu/tgm/table.do?tab=table\&init=1\&plugin=1\&language=en \&pcode=tec00001, última consulta del 23/04/2014.

9 Eurostat, GDP in PPS per cápita, datos del 24/02/2014, disponibles en http://epp.eurostat .ec.europa.eu/tgm/table.do?tab=table\&init=1\&plugin $=1 \&$ language $=e n \& p c o d e=t e c 00114$, última consulta del 23/04/2014. 
ropeas fueron responsables por el $43.2 \%$ del total emitido en el año 2008 y el $43 \%$ en 2011, seguidos por Italia y Polonia. En todos los casos ha habido una disminución más o menos significativa entre las emisiones de 2008 y las de 2011: 6\% en Alemania; casi $8.5 \%$ en Francia y $12 \%$ en Reino Unido ${ }^{10}$.

Alemania y Reino Unido se habían comprometido a formar parte de los baluartes del compromiso solidario de reducción europeo del 1PC, siendo que Francia se mostró más reticente a adquirir un compromiso individual de reducción, incluso en el marco de una agenda común, teniendo en cuenta su matriz energética y sus emisiones per cápita. Ahora bien, a partir de los datos proporcionados por la Agencia Europea de Energía (EEA por su sigla en inglés) surge que los tres Estados redujeron sus emisiones entre el 14 y $29 \%$ del año base a 2011, teniendo a Reino Unido a la cabeza ${ }^{11}$. Todos ellos sobrepasaron los compromisos asumidos en Kyoto y en base al acuerdo de reducción europea del $8 \%$.

Al analizar los motivos genuinos de tal reducción es interesante tener en cuenta lo afirmado en el inventario 2013 de emisiones de la EEA ${ }^{12}$. La UE27 logró reducir sus emisiones (sin LULUCF) en un 18.4\% entre el año base y 2011 y sólo entre 2010 y $20113.3 \%$. La UE15 contrajo sus emisiones (sin LULUCF) $14.7 \%$ del año base a 2011 y $4.2 \%$ entre 2010 y 2011. Algunos de los principales componentes de la reducción fueron: la disminución de las emisiones de las viviendas en la UE15, que se trata de uno de los cuatro módulos mayores de emisiones de GEIs europeas y que no son alcanzados por el mercado de carbono europeo (ETS por su sigla en inglés); así como una reducción en las emisiones por la electricidad y producción de calor fundamentalmente en Reino Unido y Francia. Esto último se asocia al incremento por la apuesta nuclear en Reino Unido y la reducción del consumo de gas, mientras que en el caso francés, la mengua en el uso del carbón. A lo ya mencionado, se agregan otros motivos de reducción de emisiones como la disminución del transporte en carretera, la menor producción de las industrias manufactureras excluyendo al hierro y al acero en países como Gran Bretaña $^{13}$, la menor producción de cemento en el Reino Unido, la rebaja en las emisiones por la producción de hierro y acero, y la menor producción de ácido nítrico en Francia y Reino Unido.

10 Eurostat, Total Greenhouse Gas Emissions, datos del 26/03/2013, disponible en http:// epp.eurostat.ec.europa.eu/tgm/table.do?tab=table \&init=1\&plugin $=0 \&$ language $=$ en $\&$ pcode =ten00072, última consulta del 23/04/2014.

11 European Environment Agency, Annual European Union greenhouse gas inventory 1990-2011 and inventory report 2013, op. cit., nota 8.

12 Ibid., nota 12.

13 Sólo teniendo en cuenta los tres países analizados en este apartado, pero el informe contempla a otros Estados como Grecia, España, Italia y Portugal. 
Tal como demuestra el informe de la EEA, existe un importante conjunto de datos que llevan a pensar que el principal motivo de haber logrado reducciones tan significativas en las emisiones europeas, y de estos países en particular, fue la crisis económica-financiera que causó una ralentización económica, reduciendo la producción de cemento y manufactura, el consumo energético industrial y doméstico y otras actividades mencionadas, como el transporte. Por ende, si bien dichos Estados se habían comprometido con la reducción de emisiones, la crisis ayudó a que esto fuera posible como una externalidad positiva. De hecho, la propia EEA había anunciado en diversas ocasiones previas a la finalización del período de Kyoto que existían posibilidades de que Europa no llegara a cumplir con el compromiso del $8 \%$.

En cuanto a las emisiones per cápita ${ }^{14}$, Alemania ha sido - durante todo el período - el mayor emisor y cuya cuantía no se ha visto significativamente reducida de 2008 a 2011. En contraste, Reino Unido ha logrado una reducción del $14 \%$ en sus emisiones per cápita. Tanto Alemania como Reino Unido han estado por encima de la media europea de 2008 a 2011. Recién en 2011, Reino Unido logró posicionarse por dentro de la media. El caso de Francia es muy distinto, puesto que no sólo ha reducido sus emisiones per cápita, sino que son de las más bajas de la Unión. Esto se debe a su gran apuesta por la energía nuclear. Esta condición le ha valido a Francia estar exenta de reducir sus emisiones en lo relativo al compromiso solidario del $8 \%$ suscrito en el PK.

Otro componente esencial en nuestro análisis es el consumo energético. Tradicionalmente aquellos países con mayor producto bruto interno son aquellos que presentan un mayor consumo energético. Los datos proporcionados por EEA ${ }^{15}$ confirman la presunción puesto que en 2012 los tres países que tuvieron mayores consumos energéticos de la UE28 fueron Alemania (319 Mtoe); Francia (258 Mtoe) y Reino Unido (202 Mtoe). No obstante, en el caso de Alemania ha visto incrementado su PBI en un $8.62 \%$ de 2008 a 2012 y sin embargo, ha reducido su consumo energético en $9.2 \%$ de 2006 a 2012. Francia incrementó su PBI $3.75 \%$ desde 2008 y ha reducido su consumo en $5.3 \%$. No obstante, Reino Unido no ha logrado aún recuperarse completamente de la crisis económica. Así como ha visto reducido su PBI en $6.3 \%$ de 2008 a 2012, ha experimentado una consiguiente disminución en el consumo energético del $12.2 \%$.

14 Eurostat, Greenhouse Gas Emissions per capita, datos del 19/03/2014, disponibles en http://epp.eurostat.ec.europa.eu/tgm/table.do?tab=table\&init=1\&plugin=0\&language=en\&pcode =t2020_rd300, última consulta del 23/04/2014.

15 Energy consumption down by $8 \%$ between 2006 and 2012 in the UE28, datos del 17/02/2014, disponible en http://epp.eurostat.ec.europa.eu/cache/ITY_PUBLIC/8-17022014-AP/ EN/8-17022014-AP-EN.PDF, última consulta del 23/04/2014. 
El mismo informe establece otra característica representativa de estos Estados que coincide con uno de los objetivos de la política energética de la UE. Esto es, el debate relativo a la autosuficiencia energética y la dependencia externa. La EEA afirma que entre los países más consumidores de energía, la tasa de dependencia externa es mayor, esto se aplica a los tres casos analizados con las siguientes cifras: Alemania con un $61 \%$; Francia con $48 \%$ y Reino Unido con $42 \%$. No obstante, son éstos países los mayores productores de energía de la Unión: Francia (133 Mtoe, 17\% de la producción total de UE); Alemania (124 Mtoe, $16 \%$ producción UE) y Reino Unido (116 Mtoe, $15 \%$ producción UE). Los tres Estados generan casi la mitad de la producción energética de la UE28. Alemania junto con Polonia generan más del $60 \%$ de la producción total del combustible sólido; Reino Unido produce el $60 \%$ de crudo; Reino Unido y Holanda producen el $70 \%$ de gas y finalmente en el caso de las energías renovables, Alemania y Francia generan el $30 \%$.

Así como el compromiso europeo de reducción de emisiones del 8\% es solidario, el objetivo de lograr un $20 \%$ de participación de las energías renovables en las matrices nacionales, también presenta estas características. En tal sentido, Alemania se comprometió a lograr un $18 \%$ de participación de renovables, Francia $23 \%$ y Reino Unido $15 \%$. En el contraste que muestra Eurostat a valores de marzo de 2014 sobre lo efectivamente realizado $^{16}$, resulta que hacia 2012 Alemania alcanzó $12.4 \%$; Francia $13.4 \%$ y Reino Unido $4.2 \%$. Esto significa que los tres principales emisores no cumplieron su compromiso en lo relativo a la composición de renovables de sus matrices.

En resumidas cuentas, los países analizados son las mayores economías de la Unión y se encuentran entre las principales economías mundiales. Si bien emiten en términos totales una gran cantidad de GEIs, sus emisiones per cápita se encuentran por debajo de la media de la Unión para Reino Unido y Francia en 2011, muy elevada aún en el caso germano. Todos han reducido notablemente sus emisiones totales y han mejorado su rendimiento energético aunque a partir de recetas diferenciales. Mientras Francia continúa apostando por la energía nuclear; Reino Unido ha tendido a despegarse del carbón y oscilar hacia el gas del cual es principal productor comunitario ${ }^{17}$. En comparación con otras potencias globales como Es-

${ }^{16}$ Share of renewables in energy consumption up to $14 \%$ in $2012,10 / 03 / 2014$, disponible en http://epp.eurostat.ec.europa.eu/cache/ITY_PUBLIC/8-10032014-AP/EN/8-10032014-AP -EN.PDF, última consulta del 23/04/2014.

${ }^{17}$ Los tres países abordados, junto con otros como República Checa, se habían mostrado fuertemente interesados en incrementar su producción de energía nuclear, sin embargo, lo ocurrido en Fukushima en 2011 desalentó estas intenciones. Francia es el país que más depende de este tipo de energía, puesto que cubre cerca del $40 \%$ de su capacidad energética total. 
tados Unidos, las emisiones per cápita de estos países son notablemente inferiores.

Ahora bien, nos preguntamos qué rol han jugado estos países en la construcción de la política climática europea durante el primer período de compromisos. La política climática ingresa en el debate acerca del rol de los grandes Estados, fundamentalmente de Alemania, en la conformación de las políticas públicas europeas. Coincidimos con Ulrich Speck ${ }^{18}$ al afirmar que el liderazgo alemán se encuentra acotado a la resolución de la crisis del euro en términos de hegemonía. Esto es que Alemania no tiene la voluntad política ni ciudadana de liderar al Continente. Es cierto que cumplió con su autovocación de operar como locomotora económica de la crisis en ausencia de Reino Unido de la zona euro y de la debilidad relativa de Francia. Sin embargo, apostó por las soluciones multilaterales en todos los ámbitos con un fuerte anclaje en los foros internacionales y las instituciones. Las experiencias germanas del siglo Xx han mellado el espíritu hegemónico de la nación.

Las metas europeas sobre clima y energía a 2030 y a 2050 que se encuentran en negociación resultan un ejemplo relevante para analizar los roles de los diez países propuestos. En el caso de los países estudiados en este apartado, Gran Bretaña y Francia pujaron por no determinar un porcentaje fijo en lo relativo a las energías renovables al menos para la primera parte del año. El Parlamento Europeo se había pronunciado asentando un $40 \%$ de reducción de emisiones de GEIs, un $30 \%$ de utilización de energías provenientes de fuentes renovables y un $40 \%$ de mejora en la eficiencia energética. Por su parte, Alemania se manifestó a favor de establecer un valor fijo puesto que pretende posicionarse como líder en materia de energías renovables. La sinergia de dimensiones colocó a Alemania en una posición de locomotora, aunque los resultados aún están abiertos. En tal sentido, la Comunicación 15 de 2014 de la Comisión Europea propone asumir un compromiso de reducción de emisiones de GEIs del $40 \%$ de acuerdo a los niveles de 1990 y repartido entre aquellos sectores que forman parte del mercado de carbono europeo (ETS) y los que no ${ }^{19}$; un $27 \%$ de utilización de energías renovables - como meta comunitaria no individual - con fle-

18 SPECK, U., «Why Germany is not becoming Europe's hegemón», FRIDE, n. ${ }^{\circ}$ 126, abril 2012, disponible en http://www.fride.org/descarga/PB_126_Germany_not_becoming _Europe_hegemon.pdf, última consulta del 23/04/2014.

19 Los sectores que forman parte del ETS deberán alcanzar una reducción del $43 \%$ de las emisiones de acuerdo a los niveles de 2005 y los sectores que no forman parte de ETS un $30 \%$ tomando el mismo año base. $\operatorname{COM}(2014) 15$ final, A policy framework for climate and energy in the period from 2020 to 2030, disponible en http://eur-lex.europa.eu/LexUriServ/ LexUriServ.do?uri=COM:2014:0015:FIN:ES:PDF, última consulta del 23/04/2014. 
xibilidad para que los países asuman sus propios objetivos; y se ha dejado abierta la pregunta relativa a la eficiencia energética para más adelante. Este comportamiento le ha valido a la Comisión la crítica de los partidos verdes quienes acusaron a la agencia de profundizar el distanciamiento de Europa como líder climático global que cumple un lustro. Los países que sostuvieron esta postura, particularmente Gran Bretaña y Francia plantearon que el constante aumento de los costes de la energía y los aún embates de la crisis económica financiera sobre sus industrias requieren un apoyo mayor y no restricciones de esta naturaleza. En el Consejo Europeo de Primavera se ratificó que la triple meta deberá estar lista para el mes de octubre, previo a la COP20 a celebrarse en Lima.

\section{Los ralentizadores coyunturales de la UE15: España, Grecia y Portugal}

Los tres casos analizados en este apartado presentan como principal similitud el hecho de ser economías medias de la Unión, aunque resalta el caso español que es la quinta economía de la UE28. Son países gravemente azotados por la crisis en la eurozona, de la cual forman parte, así como estuvieron eximidos de reducir sus emisiones de GEIs a partir del compromiso solidario del $8 \%$ del PK.

En cuanto a la afectación de la crisis sobre el PBI, sobresalen los casos de Grecia y Portugal. En la comparación entre el PBI griego en 2008 y en 2012 se registra una caída del 9\%, siendo que en Portugal es poco más del 2\%. España, registra su mayor impacto en 2009 y 2010 con una recuperación a partir de 2011 que se consolida con un leve incremento en $2012^{20}$. Sin embargo, el caso español mostró la afectación social de la crisis fundamentalmente en 2012 y 2013 con más de un cuarto de su población activa en situación de paro. Para abril de $2014^{21}$, se constata en Eurostat que así como Alemania se encuentra entre los países europeos con menores índices de desocupación (5.1\%), España y Grecia encabezan la tabla con 25.6 y $27.5 \%$ respectivamente.

Si bien, los tres países aquí analizados constituyen parte de la eurozona y en consecuencia, la crisis en su actividad económica ha tenido impacto en toda la UE, la gestión político-económica de la crisis fue variable al interior de los Estados. Esto ha sucedido posiblemente a resultas de las reacciones en la opinión pública y las características nacionales. Grecia no pudo ocul-

${ }^{20}$ Eurostat, GDP in PPS, op. cit., nota 9.

${ }^{21}$ Euro area unemployment rate at $11.9 \%$, abril de 2014, disponible en http://epp.eurostat .ec.europa.eu/cache/ITY_PUBLIC/3-01042014-AP/EN/3-01042014-AP-EN.PDF, última consulta del 23/04/2014. 
tar hacia 2010 la necesidad de un rescate de la Unión por haber incurrido en un déficit público inmanejable financiado por la emisión de deuda pública. Tras el primer rescate propiciado por la UE y el FMI en 2010, Grecia solicitó un nuevo rescate en 2011. El caso griego fue y sigue siendo una dura prueba para la Unión puesto que la crisis económica vino de la mano de una ingobernabilidad del país que los rescates pudieron sólo apalear en parte. La solución negociada estuvo dada por la convocatoria a elecciones en 2012. Sin embargo, hubo una división de opiniones entre los países de la eurozona que sostenían la necesidad de mantener a Grecia al interior del euro - Alemania y Francia - y aquellos más reticentes a costear dicha crisis - como algunos países nórdicos-.

Portugal fue el tercer país en solicitar el rescate, luego de Irlanda, en el año 2011. Comparte con Grecia y España la característica de tener que sortear una crisis económico-política de grandes dimensiones sin poder devaluar su moneda. La crisis precipitó la dimisión del primer ministro y se encaminó hacia una nueva etapa conservadora en la figura de su premier, así como de las recetas que encaró para recibir el rescate europeo. Recetas que significaron la privatización de activos, despidos y otras medidas de austeridad.

A diferencia de Grecia, ha mostrado mayores signos de recuperación sin que sea necesario ejecutar un segundo rescate. Sin embargo, el paro continúa siendo preocupante, con valores de $15.3 \%$ según el informe de Eurostat. La crisis política ha ido en aumento con dos dimisiones a mediados de 2013 de los ministros de finanzas y de relaciones exteriores. Con esto, y dados los esfuerzos por sostener la situación sin llegar a un default, la troika conformada por el Banco Central Europeo, la UE y el FMI, concedieron a Portugal una extensión del plazo hasta 2015 para alcanzar la meta de reducir su déficit por debajo del $3 \%$ aunque se calcula que su deuda está por encima del $130 \%$ del $\mathrm{PBI}^{22}$.

En el caso español, si bien el inicio de la crisis conllevó un cambio de signo político del PSOE al PP - aunque no puede plantearse una explicación monocausal para el resultado electoral-, la presidencia de Mariano Rajoy ha logrado sostenerse desde 2011. Asimismo, España se ha mostrado reticente a reconocer que ha sido objeto del rescate europeo desde 2011, de hecho, tanto el presidente Rodríguez Zapatero como Rajoy fueron muy elocuentes en sus discursos planteando que su país no requería este tipo de salvamento y plasmaron el acuerdo político PP-PSOE en una reforma constitucional. Las medidas de austeridad comenzaron durante

${ }^{22}$ Cronología de la crisis disponible en http://www.rtve.es/noticias/20140319/cronologia -crisis-portugal/419261.shtml y datos estadísticos del Instituto Nacional de Estadística de Portugal en http://www.ine.pt/, última consulta del 23/04/2014. 
los últimos años del gobierno socialista y se han extendido hasta 2014 a pesar de la resistencia social. Si bien en 2012 hubo una leve recuperación de la actividad económica, el aumento de los tipos de interés afectó el acceso al mercado de capitales con el consiguiente salvataje a las instituciones bancarias.

La evolución de los PBI de 2008 a 2012 denota la caída productiva en 2009 y la leve recuperación en 2011 teniendo al caso español a la cabeza. En cuanto a los productos per cápita ${ }^{23}$, en todos los casos se registra una caída, siendo la más pronunciada la de Grecia con casi un $20 \%$, seguida por un $7.7 \%$ en España y un $2.6 \%$ en Portugal. España ocupa en la tabla europea el lugar décimo catorce, Portugal el décimo noveno y Grecia el vigésimo primero.

Los datos de Eurostat muestran las importantes diferencias en las emisiones totales de países analizados ${ }^{24}$. Para 2011, Grecia emitió un tercio del valor emitido por España, y Portugal un 20\% del español. Sin embargo, esto debe contrastarse con las diferencias en sus PBI, puesto que el PBI español es entre 5 y 6 veces mayor que el griego y el lusitano.

Ahora bien, en todos los casos se ha registrado una disminución ostensible que oscila entre 10 y $12 \%$ en las emisiones totales comparando el valor de 2008 con el de 2011. Esta reducción creemos se debe a una doble cuestión, por un lado, los efectos de la crisis económica, y por otro, la participación de estos países en las acciones europeas de reducción de emisiones, como ETS. Sin embargo, ninguno de los tres Estados se encontraba obligado a reducir sus emisiones durante el 1 $\mathrm{PC}^{25}$. La decisión 358 del Consejo de la UE de 2002, autorizó a España a emitir hasta 15\% más comparado con los valores del año base; $25 \%$ a Grecia y $27 \%$ a Portugal. No obstante, España sobrepasó su cuota en $6 \%$, siendo que emitió un $21 \%$ más relativo a las emisiones del año base en 2011. Tanto Grecia como Portugal estuvieron por dentro de la meta comunitaria, siendo que la primera incrementó sus emisiones en $7.5 \%$ y Portugal en $16.4 \%$. El hecho de que estos dos países hayan cumplido con los objetivos comunitarios, no significa no sea preocupante que hayan continuado un proceso ascendente de emisiones en lugar de oscilar hacia economías de bajo carbono.

En 2011 es posible avizorar un importante aumento en las emisiones de los tres Estados respecto al año base. La más relevante es la de España por encima del 20\%, seguida por Portugal y Grecia. Del mismo modo, los tres países han disminuido sus emisiones per cápita durante el 1PC del PK

${ }^{23}$ Eurostat, GDP in PPS per capita, op. cit., nota 10.

24 Eurostat, Total Greenhouse Gas Emissions, op. cit., nota 11.

25 Council Decision 2002/358/EC, disponible en http://eur-lex.europa.eu/LexUriServ/ LexUriServ.do?uri=CELEX:32002D0358:EN:HTML, última consulta del 23/04/2014. 
aunque resalta el caso griego con una reducción del $55 \%{ }^{26}$. Por otro lado, y dado que este indicador se liga directamente con la variable población, es posible afirmar que España es uno de los países más poblados de la UE con casi 47 millones de habitantes (entre 45 y 46 millones de 2008 a 2011), contrastando con Grecia y Portugal que en ambos casos detentan entre 10 y 11 millones de habitantes aproximadamente. Si bien las emisiones totales de España en 2011 triplican las de Grecia y quintuplican las portuguesas, así como que el aumento de emisiones español desde el período base de Kyoto ha sido desproporcionado, las emisiones per cápita de los tres Estados tienden a igualarse. Esta igualación demuestra que sobretodo la actividad griega ha sido la más apremiante en términos de emisiones per cápita durante todo el período analizado. De igual modo, todos han permanecido por debajo de la media europea, excluyendo a Grecia en 2008.

En cuanto a la participación de energías renovables en el consumo energético y teniendo en cuenta los datos de Eurostat a marzo de $2014^{27}$, surge que España debía participar en el compromiso europeo del 20\% a 2020 con un 20\%; Portugal con $31 \%$ y Grecia con $18 \%$. De estos valores y a 2012, España ha logrado un 14.3\%; Grecia $15.1 \%$ y Portugal $24.6 \%$.

Otro indicador que permite constatar las afirmaciones relativas al caso español, es la intensidad carbónica que mide la relación entre aumento/disminución del PBI y de las emisiones totales. Al comparar el PBI español de 2008 y 2011 resulta que tuvo una disminución del 1.2\%, siendo que las emisiones se han visto reducidas en algo más de diez puntos.

La intensidad de emisiones de GEIs por consumo energético muestra la carbonización de las matrices energéticas. Si bien todos los casos se encuentran por debajo de la medida europea en 1990 y 2008, hacia 2011 resalta el caso griego. No obstante, y al aplicar al indicador precedente el indicador de intensidad carbónica en el uso energético ${ }^{28}$, podemos comprobar cómo los tres países han disminuido sus intensidades desde el año base y específicamente de 2001 a 2011. El indicador de intensidad carbónica en el uso energético sirve para comprobar los mixes energéticos entre el uso de fuentes renovables y no renovables. La intensidad carbónica ha disminuido en la UE28 con mayores momentos de reducción entre 2007 y 2008 $(-1.6 \%)$ y entre 2008 y $2009(-1.7 \%)$. Al calcular la variación de la intensidad de los tres países entre 2001 y 2011, notamos que España ha reducido su intensidad en $8.19 \%$, Grecia en $2.61 \%$ y Portugal en $16.37 \%$.

${ }^{26}$ Eurostat, Greenhouse Gas Emissions per capita, op. cit., nota 15.

27 Share of renewables in energy consumption up to $14 \%$ in 2012, op. cit., nota 17.

28 Energy, transport and environment indicators, 2013, disponible en http://epp.eurostat .ec.europa.eu/cache/ITY_OFFPUB/KS-DK-13-001/EN/KS-DK-13-001-EN.PDF, última consulta del 23/04/2014. 
Con toda la información explicitada, es posible afirmar que los tres países han sido algunos de los más azotados por la crisis en la eurozona. Las respuestas político-económicas a la crisis han sido disímiles pero comparten la receta aplicada y solicitada por las instituciones europeas. Los resultados de dicha receta aún se encuentran bajo observaciones, puesto que si bien los índices económicos han repuntado, algunos indicadores sociales siguen en niveles preocupantes. En este marco, la receta escogida fue de tipo conservadora, teniendo como prueba que uno de los primeros recortes se dio en los subsidios a las energías renovables, con énfasis en el caso español.

España fue uno de los líderes europeos en materia de energías renovables, a través de la subvención a nuevos establecimientos que produjesen energía eólica y solar entre otras. Ahora bien, a este sistema de subsidios se adicionó un déficit tarifario de la energía eléctrica en el país que las autoridades han leído como la falta de interconectividad en la Península Ibérica y la necesidad de abastecer a sus mercados. Estas características de la política energética española hicieron colisión con la crisis de la zona euro y los recortes presupuestarios. La moratoria en las ayudas a los nuevos emprendimientos de energías renovables fue sólo un eslabón de medidas. Uno de los últimos estudios presentados por la firma Bloomberg New Energy Finance (BNEF) afirma que el volumen de inversión en energías limpias en todo el mundo cayó un $11 \%$ en 2013, siendo que España lidera dicha caída de inversiones, con una reducción del $68 \%{ }^{29}$.

El Consejo Europeo de Primavera celebrado a mediados de marzo de 2014 en Bruselas ${ }^{30}$, reconoció el problema de la interconectividad ibérica como propio, puesto que en el marco de la Crisis en Ucrania, la cuestión de la dependencia energética de Rusia se volvió un eje geoestratégico además de un objetivo de la política energética y climática. El presidente español, Mariano Rajoy, y el presidente portugués, Pedro Passos Coelho, emprendieron una cruzada satisfactoria para lograr que entre las conclusiones del encuentro apareciese la relevancia de incrementar la interconectividad ibérica. A tono estuvieron los discursos del presidente del Consejo Europeo, Herman Van Rompuy, y del presidente de la Comisión Europea, Juan Manuel Barroso $^{31}$. Esperan que dicho reconocimiento se traduzca en una asignación

29 Clean Energy Investment - Q4 2013 Fact Pack, disponible en http://about.bnef.com/ presentations/clean-energy-investment-q4-2013-fact-pack/, y New Investment In Clean Energy Fell 11\% In 2012, disponible en http://about.bnef.com/press-releases/new-investment -in-clean-energy-fell-11-in-2012-2/, última consulta del 23/04/2014.

30 Para ampliar ver en http://register.consilium.europa.eu/doc/srv?l=EN\&t=PDF\&gc= true \&sc $=$ false \&f=ST\%207\%202014\%20INIT, última consulta del 5/06/2014.

31 Sitio web de TV NewsRoom European Council, disponible en http://tvnewsroom .consilium.europa.eu/event/european-council-march-2014-day-2, última consulta del 23/04/2014. 
de fondos europeos al financiamiento de la interconexión que en palabras de Rajoy amplificará el potencial de renovables con el que cuenta España y que ha podido explotar sólo parcialmente.

\section{Los nuevos ralentizadores o contrapesos: República Checa, Polonia, Bulgaria y Rumanía}

Se trata de cuatro países que comparten su pertenencia a Europa del Este y su reciente ingreso en la UE, además de estar por fuera de la zona euro. Sus ingresos datan de 2004 en el caso de República Checa y Polonia; y de 2007 para Rumanía y Bulgaria. Mientras la economía polaca es la mayor de Europa del Este - y mayor que algunos países de la UE15 como Grecia o Portugal - Bulgaria es una de las menores economías de la UE junto con Lituania, Latvia, Chipre, Estonia y Malta.

De la evolución del PBI durante el 1PC surge que todas las economías experimentaron fuertes reducciones en sus productos entre 2008 y 2009, con mejoras en 2011. El caso polaco muestra una reducción de casi 15\% en dicho período y si bien en la comparación 2008-2012 aún se percibe un $-2.2 \%$, a partir de 2011 ha transcurrido un sendero ascendente. República Checa sostuvo una reducción de $8.44 \%$ de 2008 a 2009, aunque ha podido recuperarse hacia 2011. En consecuencia, la comparación de los productos 2008 y 2012 arroja un valor positivo del 1.3\%. Rumanía experimentó un fuerte descenso de 2008 a 2009 de casi $16 \%$, y aún de 2008 a 2012 se percibe una baja de $2.86 \%$ aunque mejorando. Finalmente, resalta el caso búlgaro porque se ha mantenido constante a lo largo del plazo más crítico de 2008 a 2009 y si bien no se cuenta con el dato del producto a 2012 en Eurostat, la tendencia 2010 a 2011 era de $8.33 \%$ ascendente ${ }^{32}$.

$\mathrm{El}$ producto bruto per cápita muestra algunas cuestiones interesantes para los países del Este europeo ${ }^{33}$. Tanto en 2008 como en 2012 los cuatro países se encontraban muy por debajo de la media europea. Además, en el mismo plazo, Polonia se posicionaba por debajo de los valores de República Checa, así como de Grecia y Portugal, a pesar de contar con un PBI que duplicaba o triplicaba los valores de éstos, dependiendo del caso. Resalta también la similitud en 2012 del PBI per cápita de Rumanía y Bulgaria a pesar de las diferencias entre sus PBI nominales. En la evolución 2008-2012, se percibe la estabilidad en República Checa, así como en los casos rumanos y búlgaro - con leves ascensos - siendo que Polonia logró en el mismo pe-

32 Eurostat, GDP in PPS, op. cit., nota 9.

33 Eurostat, GDP in PPS per capita, op. cit., nota 10. 
ríodo incrementar sus valores en diez puntos. Para 2012 República Checa ocupaba el décimo octavo lugar de la tabla europea, siendo que Polonia se ubicaba en el vigésimo quinto lugar, quedando Rumania y Bulgaria en los últimos puestos de la tabla del PBI per cápita europeo.

Desplazándonos hacia el terreno de las emisiones, resulta que en todos los casos, la disminución en la actividad económica que se constata en la afectación del PBI de 2008 a 2009, tuvo una correspondencia en la disminución del valor de GEIs emitido. Es por ese motivo también, que al momento que las economías recobraron signos económicos positivos, incrementaron sus emisiones. No obstante, aunque los PBI han vuelto a los valores previos a la crisis, las emisiones checas se han visto reducidas al igual que las polacas aunque en un grado menor. Resaltan los casos de Rumanía y Bulgaria que fueron en 2011 los países de la UE que registraron un mayor incremento en sus emisiones totales ${ }^{34}$.

Los cuatro países se encontraban por fuera de la meta solidaria del $8 \%$ europeo relativo al 1PC, y puesto que ingresaron luego de tal decisión comunitaria, se incorporaron a los anexos del PK asumiendo reducciones individuales del $8 \%$ y del $6 \%$ para Polonia. Tomando como base los datos del inventario anual europeo de emisiones de GEIs, los cuatro países realizaron reducciones ostensibles en sus emisiones tomando como base el año 1990. La lista la encabezan Rumanía y Bulgaria con reducciones mayores al 50\%, seguidas por República Checa y Polonia con reducciones del 30\%. Sin embargo, de 2010 a 2011 Bulgaria y Rumanía incrementaron sus emisiones en lugar de reducirlas como fue el caso checo y polaco.

Al igual que ocurría en la comparación entre España, Grecia y Portugal donde debe valorarse la desproporción entre el tamaño de una y otras economías, aquí sucede lo mismo al respecto de Polonia. El producto polaco en 2012 duplicaba el checo y el rumano, y en 2011 el producto búlgaro representaba un $10 \%$ del producto polaco. No obstante, y en el terreno de las emisiones totales, las emisiones de GEIs de Polonia en 2011 triplicaron las checas y rumanas. Con Bulgaria la afirmación se revierte por cuanto la relación del 10\% del PBI no se reproduce proporcionalmente en las emisiones, sino que las emisiones búlgaras son poco más del $16 \%$ de las polacas.

En cuanto a las emisiones per cápita ${ }^{35}$, es posible afirmar que para 2008 tanto Polonia como República Checa se encontraban por fuera de la media europea. Esta circunstancia se repite a lo largo de los cuatro años analizados. $\mathrm{Si}$ bien Bulgaria se encuentra por debajo de la media, es por poco margen. Si tomamos los tres grupos de países analizados, para 2011 son Alemania, Gre-

${ }^{34}$ Eurostat, Total Greenhouse Gas Emissions, op. cit., nota 11.

35 Eurostat, Greenhouse Gas Emissions per capita, op. cit., nota 15. 
cia, Polonia y República Checa los cuatro países con mayores emisiones per cápita de la UE. Si tomamos los 28, el caso de Luxemburgo surge por duplicar los valores del resto de las partes, seguido por los mencionados así como Bélgica, Dinamarca, Estonia, Irlanda, Chipre, Países Bajos y Finlandia. Todos ellos, se encuentra por encima de la media europea en 2011.

Tres de los cuatro países han reducido sus emisiones per cápita de 2008 a 2012 en valores variables, mientras Rumanía ha logrado reducir 12\%, República Checa $7 \%$ y Polonia 1.24\%, Bulgaria ha incrementado sus emisiones per cápita en $2.4 \%$.

En cuanto a la participación de las energías renovables en el consumo energético, los compromisos en el marco del 20\% europeo se repartían de la siguiente forma: Bulgaria 16\%; República Checa 13\%; Polonia 15\% y Rumanía 24\%. Bulgaria es el primer de estos Estados en haber alcanzado su objetivo en el año 2011, siendo que para 2012 Polonia ha logrado el 11\%; República Checa $11.2 \%$ y Rumanía $22.9 \%^{36}$. En términos de intensidad de emisiones de GEIs por consumo energético, República Checa se ha mantenido por debajo de la media europea que osciló de 93.9 a 91.4 entre 2008 y 2011 y alcanzó una reducción del 1.6\%. Bulgaria ha sido el más intenso y en constante aumento desde 2008 exceptuando la baja de 2009. El aumento total en la intensidad de 2008 a 2012 roza los tres puntos. Tanto Polonia como Rumanía han reducido sus intensidades en $3 \%^{37}$.

Ahora bien, las diferencias entre estos países exceden la actividad económica y sus emisiones e intensidades, para profundizarse en el plano político y el rol que plantean tener en la Unión. Si bien República Checa es un país cuyo rendimiento económico, climático y energético ha venido incrementándose, su perfil político dista del polaco. Polonia es un Estado mediano de la UE, con un PBI más cercano a los grandes que a los pequeños, posicionándose como la novena economía. Ha mostrado una búsqueda de liderar procesos políticos ligados al clima y a la energía a pesar de su alta dependencia al carbón. Fue anfitrión de la COP19 del CMNUCC, celebrada en noviembre de 2013 en Varsovia, como ya lo había sido en 2008 en la COP14 en Poznan.

Ahora bien, ese liderazgo no se ha caracterizado por incrementar los objetivos comunitarios, sino por ralentizarlos. La propia organización de la COP19 estuvo sometida a una serie de circunstancias que empañaron el ya de por sí complejo horizonte de éxito de la conferencia. Una de ellas fue la organización paralela a la COP19 de la Cumbre del Clima y el Carbón aus-

36 Share of renewables in energy consumption up to $14 \%$ in 2012, op. cit., nota 17 .

37 Greenhouse gas emissions intensity of energy consumption, 10/04/2014, disponible en http://epp.eurostat.ec.europa.eu/tgm/table.do?tab=table\&init=1\&plugin=0 \&language $=$ en\&pcode=tsdcc220, última consulta del 23/04/2014. 
piciada por el gobierno de Polonia y la Asociación Mundial del Carbón que reunió a algunas de las compañías más representativas del sector. Como si el hecho de que las organizaciones de la sociedad civil se opusieran a la celebración de la conferencia en Polonia por su doble estándar en materia climática no fuera suficiente, en el marco del segmento de alto nivel, el Primer Ministro polaco, Donald Tusk, desplazó de su cargo al Ministro de Ambiente, Marcin Korolec, quien presidía la COP19 y había liderado el proceso negociador previo a la conferencia. Como forma de palear la crisis doméstica con fuerte impacto internacional, Tusk adujo que Korolec seguiría operando como ministro plenipotenciario de Polonia en la COP.

Del mismo modo, desde su ingreso en la UE, Polonia se ha dedicado a vetar y amenazar con vetar algunas de las iniciativas climáticas que prevén reducciones de emisiones más ambiciosas hacia 2030 y 2050. Algunos ejemplos son, previo a la COP15, minar el consenso interno entorno a que Europa asumiera un compromiso solidario de reducción del 30\% en el 2PC del PK. Dicho país anunció que no aceptaría un compromiso de reducción tan ambicioso sin conocer previamente el financiamiento dispuesto por las principales economía europeas. Asimismo, en 2011 y 2012, Polonia vetó la generación de los compromisos de largo plazo de reducción de emisiones europeos hacia 2050. De esta forma, logró ralentizar un proceso que había alcanzado el favor de los 26 socios restantes. Así como la UE se trazó en 2008 la propuesta 20/20/20, desde allí ha caminado hacia el horizonte 2030 y 2050 . Para ello se ha asentado la opinión de que Europa debe lograr una reducción de emisiones de GEIs entre $80-90 \%$ para 2050 y del $40 \%$ para $2030^{38}$.

Dos de los principales argumentos esgrimidos por Polonia para comportarse de este modo son: que el carbón garantiza entre el 80 y $90 \%$ de su abastecimiento eléctrico; así como la continuidad en el autoabastecimiento energético. Este argumento ha cobrado fuerza en el marco del conflicto en Ucrania, puesto que la principal preocupación de la UE previo a tomar medidas más radicales con Rusia en cuanto a su anexión de la Península de Crimea, es lograr prescindir del gas que Europa compra a Rusia anualmente. A este respecto, Polonia ha pretendido jugar un rol central como mediador en el conflicto de Ucrania. De hecho, la crisis ha relanzado el denominado «triángulo de Weimar» compuesto por Alemania, Francia y Polonia. Los tres ministros de relaciones exteriores han tenido un alto perfil en la gestión que tanto la UE como la OTAN hacen de la crisis.

${ }^{38}$ Polonia ha hecho uso de esta herramienta por cuanto se trata de una decisión que requiere unanimidad de los votos. 
Además, Polonia ha dado una aceptación expresa y también ligada a la salida de Korolec del gobierno, al shale gas o explotación no convencional que ha colocado - junto con Gran Bretaña, Hungría y República Checaa la UE en la posición de no condenar la actividad, aunque la Comisión en enero de 2014 produjo una recomendación y una comunicación para prever estándares ambientales mínimos en el fracking ${ }^{39}$.

Considerando todo lo afirmado en este apartado, es posible aseverar que este grupo encabezado por Polonia representa para la Unión un modelo de limitación de su ambición climática posterior a 2020. También es cierto que muchas veces los propios países que ofician de locomotoras se han valido de la posición polaca para apoyar compromisos menos ambiciosos. En consecuencia, creemos que este grupo y Polonia en particular representa la máxima expresión del doble estándar europeo en materia de CBDR. Esto sucede porque los países aquí analizados utilizan el argumento de las mayores obligaciones históricas de los socios mayores para no asumir compromisos europeos. Este poder se asocia a las responsabilidades y es justificado por Europa tanto en tal carácter como por la necesidad de alcanzar unanimidad de opiniones para la toma de decisiones. No obstante, en su aplicación externa a la UE, dicho principio se vuelve más restrictivo de reunión en reunión.

\section{La internacionalización de la política climática europea}

En función del recorte temporal de esta contribución (2008-2014), reconocemos la existencia de dos etapas: por un lado de 2008 a 2009; y por otro, de 2010 a 2014. Ahora bien, asumimos que las características de la primera fase se desarrollan a partir de la misma construcción del régimen climático internacional y fundamentalmente con la firma y entrada en vigor

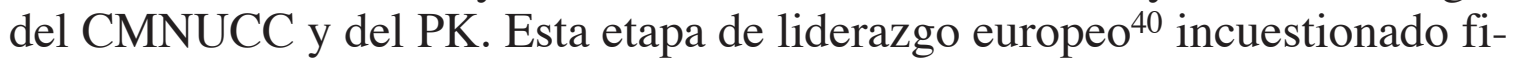

$39 \mathrm{COM} / 2014 / 023$ final, disponible en http://eur-lex.europa.eu/legal-content/EN/ TXT/?uri=CELEX:52014DC0023, última consulta del 23/04/2014.

40 Existe una amplia bibliografía respecto al liderazgo climático europeo, sólo a manera de ejemplificación mencionamos los siguientes aportes: GARCÍA LUPIOLA, A., «La política medioambiental de la Unión Europea ante el cambio climático», en Medio Ambiente \& Derecho: Revista electrónica de derecho ambiental, n. ${ }^{\circ}$ 18, 2009; GARCÍA LUPIOLA, A., «Novedades en la política europea de medio ambiente: el desarrollo sostenible y la lucha contra el cambio climático en la estrategia Europa 2020», en Unión Europea Aranzadi, n. ${ }^{\circ}$ 6, 2011, pp. 45-54; GARCÍA LUPIOLA, A., «La Unión Europea en la Conferencia sobre cambio climático de Copenhague: lucha frustrada a favor de un texto jurídicamente vinculante», en $M e$ dio Ambiente \& Derecho: Revista electrónica de derecho ambiental, n. ${ }^{\circ}$ 21, 2010; LÓPEZ LÓPEZ, A., «La política medioambiental de la UE en materia de cambio climático», en $O b$ - 
naliza con la bisagra climática que supone la celebración de la COP15 en la ciudad de Copenhague. Es así que la segunda etapa conlleva una nueva búsqueda de Europa por continuar ocupando un lugar que detentaba y que ahora es cuestionado desde dentro y fuera.

Las condiciones del liderazgo climático incuestionado de la UE difícilmente puedan volver a repetirse, fueron óptimas para alcanzar una posición de prestigio cuya clave fue un proceso de retroalimentación entre las variables domésticas y externas de Europa. Algunos de los principales elementos de la política climática europea que la posicionaron en este rol fueron: la relación clima-energía; la estrategia de adelantarse; los compromisos solidarios de reducción de acuerdo al ingreso de nuevos miembros; el ETS y la sinergia entre estos elementos que la convirtieron en Potencia Climática Moral.

La estrategia europea de adelantarse fue promovida a través de una sólida maquinaria institucional y jurídica al interior del bloque. Se constata la introducción del ambiente como objetivo de la UE en relación al desarrollo tanto en el Tratado de Maastricht como en el Tratado de Áms-

servatorio Medioambiental, Vol. 5, 2002, pp. 163-191; STERLING, A.Y., «Diseño del PostKioto, opciones, principios, objetivos y políticas sobre cambio climático en la UE, frente al segundo período de compromiso», en Observatorio Medioambiental, n. ${ }^{\circ}$ 8, 2005, pp. 271-289; PÉREZ DE LAS HERAS, B., «Climate change and energy in the EU: global challenges, collective responsabilities», en European Strategy Project, EGS 4/2013, abril de 2013; PÉREZ DE LAS HERAS, B., «Beyond Kyoto: The EU's Contribution to a More Sustainable World Economy», en European Law Journal, Vol. 19, No. 4, July 2013, pp. 577-593; FERNÁNDEZ EGEA, R., SINDICO, F., «El papel de la UE en la lucha contra el cambio climático: ¿líder en la política climática global?», en Revista electrónica de estudios internacionales, n. ${ }^{\circ}$ 14, 2007; AGUDO GONZÁLEZ, J., TRUJILLO PARRA, L., «Perspectiva del derecho del medio ambiente y de las políticas ambientales de la Unión Europea», en Revista Catalana de Dret ambiental, Vol. IV, n. ${ }^{\circ}$ 1, 2013; ESCRIBANO ÚBEDA-PORTUGUÉS, J., «Cambio climático, política, economía y derecho. Desafíos para la comunidad internacional», Instituto de Estudios Internacionales y Europeos. Francisco de Vitoria, Colección electrónica, n. ${ }^{\circ} 3$, 2013; ATIENZA SERNA, L., «La energía eléctrica y el desarrollo sostenible», en Cuadernos Europeos de Deusto, n. ${ }^{\circ}$ 42, 2010, pp. 15-40; BARREIRA LÓPEZ, A., «El papel de la UE en las negociaciones de cambio climático», en Cuadernos Europeos de Deusto, n. ${ }^{\circ} 42,2010$, pp. 41-57; CISCAR, J. C., «Aspectos económicos de la política climática europea», en Cuadernos Europeos de Deusto, n. ${ }^{\circ}$ 42, 2010, pp. 59-72; FERNÁNDEZ SÁNCHEZ, P, «El almacenamiento de dióxido de carbono en los espacios marinos de la UE», en Cuadernos Europeos de Deusto, n. ${ }^{\circ}$ 42, 2010, pp. 73-100; GILES CARNERO, R. M., «La Reunión de Copenhague de 2009: Las nuevas negociaciones en torno al Principio de Responsabilidades comunes pero diferenciadas», en Cuadernos Europeos de Deusto, n. ${ }^{\circ} 42,2012$, pp. 125-153; YOUNGS. R., «The EU's global climate and energy policies: gathering momentum?», FRIDE Working Paper, n. ${ }^{\circ}$ 118, abril 2013; HAMANN, P., «La Unión Europea y el cambio climático: La iniciación del comercio de derechos de emisiones como sistema de gobernanza de múltiples niveles», Tesis para optar al grado de Magíster en Estudios Internacionales, Instituto de Estudios Internacionales, Universidad de Chile, 2013. 
terdam, cuyo referendo se realiza a través de la relevancia del desarrollo sustentable en el Tratado de la Unión Europea (TUE) y en el Tratado de la Comunidad Europea (TCE). Sin embargo, y tal como anuncia Asier García Lupiola ${ }^{41}$, el Tratado de Lisboa ${ }^{42}$ introdujo la ampliación del cuarto objetivo de la política ambiental al mencionar la lucha contra el cambio climático. Asimismo, Lisboa, a través del artículo 194 de TFUE, reguló la política energética.

Además de los tratados fundacionales de la UE, existen otros instrumentos que otorgan la base de sustentación de la política climática comunitaria. Uno de ellos son los Programas de Acción sobre Medio Ambiente ${ }^{43}$. En 1986 - en el marco del III Programa - se introdujo al calentamiento global en la agenda comunitaria. Por su parte, el V Programa asumió cuatro temas centrales en la cooperación internacional ambiental y allí mencionó al cambio climático en primer lugar. El VI Programa propuso superar el enfoque estrictamente legislativo ambiental y promover una lógica más estratégica. En tal sentido afirmó que: «el cambio climático es el principal reto para los próximos 10 años». Finalmente el VII Programa afianzó los objetivos ambientales y climáticos 2020.

Del mismo modo, el cambio climático fue reconocido como uno de los problemas más desafiantes del ambiente en el Consejo Europeo de Viena celebrado en diciembre de 1998. De caras al inicio de nuevo milenio, la UE delineó por primera vez un Programa Europeo sobre Cambio Climático $(\mathrm{PECC})^{44}$ en el año 2000 junto con la presentación de un Libro Verde de la Comisión y ligado al comercio de derechos de emisión de GEIs. El sistema fue establecido formalmente tres años más tarde, a partir de la Directiva 2003/87/CE del Parlamento y del Consejo del 13/10/2003. Tal como anuncian diversos analistas, entre ellos Beatriz Pérez de las Heras ${ }^{45}$, ETS cons-

41 GARCÍA LUPIOLA, A., «La política medioambiental de la Unión Europea ante el cambio climático», en Medio Ambiente \& Derecho: Revista electrónica de derecho ambiental, n. ${ }^{\circ} 18,2009$.

${ }^{42}$ El Tratado de Lisboa de 2007 - en vigor desde 2009- instituye el TUE y el Tratado de Funcionamiento de la Unión Europea (TFUE), dejando de lado el TCE. De esta forma, ni el ambiente ni la sustentabilidad quedan desprotegidos en la medida que quedan manifiestos en los artículos 3.3 de TUE; 3.5 TUE; 4 TUE y 11 TFUE, entre otros.

43 I Programa de Acción de Medio Ambiente (1973-19779; II Programa de Acción de Medio Ambiente (1977-1983); III Programa de Acción de Medio Ambiente (1983-1987); IV Programa de Acción de Medio Ambiente (1987-1992); V Programa de Acción de Medio Ambiente (1992-2000); VI Programa de Acción de Medio Ambiente (2000-2012) y VII Programa de Acción de Medio Ambiente (2012-2020).

${ }_{44} \mathrm{PECC}, \mathrm{COM} / 2000 / 0088$, disponible en http://eur-lex.europa.eu/legal-content/ES/ TXT/?uri=CELEX:52000DC0088, última consulta del 23/04/2014.

45 PÉREZ DE LAS HERAS, B., «Beyond Kyoto: The EU's Contribution to a More Sustainable World Economy», en European Law Journal, Vol. 19, No. 4, July 2013, pp. 577-593. 
tituyó uno de los principales baluartes del compromiso climático de reducción europeo.

A partir de la generación de ETS, muchas de las normas comunitarias ligadas al cambio del clima se centraron en el mercado. La Directiva 2004/101 vinculó el ETS con los mecanismos de flexibilidad establecidos en el Protocolo de Kyoto, con miras a su entrada en vigor en el año 2005. Del mismo modo, la Decisión 280/2004/EC estableció un mecanismo de monitoreo de emisiones de la UE y la implementación del PK.

Hay cierto consenso entre los analistas que la Comunicación titulada: «Ganar la batalla contra el cambio climático mundial» de 2005 ha sido esencial en la política climática europea ${ }^{46}$, puesto que implantó el compromiso 20-20-20. Esto es: reducir las emisiones del GEIs en 20\%; reducir el consumo de energía en $20 \%$ y mejorar el rendimiento energético y satisfacer el 20\% de las necesidades energéticas con fuentes renovables para 2020. En esta misma línea han marchado el II PECC de $2005^{47}$, el cual asumió la necesidad de alcanzar la reducción del $8 \%$ en función del PK; sensibilizar a la ciudadanía para generar cambios de comportamiento; incrementar la investigación climática para mejorar los esfuerzos de mitigación y promover la cooperación con terceros Estados, fundamentalmente países en desarro11 .

Igualmente, han sido esenciales el informe «Limitar el calentamiento mundial a $2{ }^{\circ} \mathrm{C}$, medidas necesarias hasta 2020 y después» de $2007^{48}$ junto con la presentación - en el mismo año - del Libro Verde de adaptación al cambio climático en Europa $^{49}$. En cuanto al primer informe, la Comunicación incrementó la apuesta 20-20-20 al establecer como objetivo reducir en un 30\% las emisiones de GEIs a 2020 (respecto de los niveles de 1990). Propuesta que la UE llevó a la COP 13 en Bali y reiteró en la COP15 en Copenhague, aunque finalmente en la enmienda de Doha se comprometió a reducir un $20 \%$ y hasta un $30 \%$ en caso de que otros países hicieran lo mismo. El Informe aludido establece que para 2050 las emisiones mundiales deberían disminuir en un $50 \%$ respecto a 1990 , lo que supone reducciones en los países desarrollados del orden del 60 al 80\%. Esto no descuida que si bien son los países desarrollados quienes deben reducir en mayor

46 Ganar la batalla contra el cambio climático mundial, 9/02/2005, Disponible en http:// eur-lex.europa.eu/legal-content/ES/TXT/?uri=CELEX:52005DC0035, última consulta del 23/04/2013.

${ }^{47}$ II PECC, octubre de 2005, disponible en http://ec.europa.eu/clima/policies/eccp/second/index_en.htm, última consulta del 23/04/2014.

${ }_{48} \mathrm{COM}$ (2007) 2 final, disponible en http://eur-lex.europa.eu/LexUriServ/LexUriServ.do? uri=COM:2007:0002:FIN:ES:PDF, última consulta del 23/04/2014.

49 COM (2007) 354 final, 26/06/2007, disponible en http://eur-lex.europa.eu/legal -content/ES/TXT/?uri=CELEX:52007DC0354, última consulta del 23/04/2014. 
medida, algunos países en desarrollo deberían hacer lo mismo, argumento coincidente con la lectura europea de CBDR y las capacidades respectivas.

La solidaridad expresada tanto en el objetivo de reducción del $8 \%$ como del 20\%, es para Beatriz Pérez de la Heras ${ }^{50}$ una forma de plasmar CBDR legitimado en el CMNUCC. No obstante, no podemos dejar de notar que existe una diferencia vital entre la aplicación interna y externa que Europa ha realizado del mismo. Para adentrarnos en este aspecto, resulta preciso establecer las diferentes lecturas estatales relativas al principio de CBDR. A grandes rasgos es posible agruparlas en dos posturas. Primeramente la que sostienen la Unión Europea, el Umbrella Group ${ }^{51}$, el Grupo de Integridad Ambiental ${ }^{52}$ y el reciente AILAC liderado por Colombia y Chile $^{53}$. Esta postura se basa en la integración entre CBDR y lo que llaman las capacidades respectivas. Esto obligaría a países como China a formar parte de un régimen obligatorio de reducciones puesto que si bien su responsabilidad en el calentamiento climático global es más reciente que la de algunos países desarrollados; sus capacidades actuales declinan dicha ventaja.

La segunda postura y contrapuesta a la anterior, es la del G77 + China, BASIC y los países árabes, quienes asumen una identidad entre CBDR y el principio de responsabilidades históricas. Esta lectura hace hincapié en que son los países desarrollados quienes de acuerdo a la CMNUCC en su artículo 3, deben asumir el liderazgo de reducción por cuanto han sido los principales responsables de las emisiones históricas desde la Revolución Industrial y hasta hace pocos años; y por ende, del cambio del clima global.

Otros grupos como AOSIS (Alianza de Pequeños Países Insulares), los PMA (Países Menos Adelantados) y el Grupo Africano, muestran un discurso que a veces coincide con la primera y otras con la segunda lectura.

Ahora bien, podría hablarse de un doble estándar europeo en la aplicación de CBDR hacia adentro y hacia afuera de la Unión, puesto que mientras reconoce e institucionaliza las responsabilidades diferenciadas tal como queda plasmado en la distribución de limitación y generación de emisiones a países como España o los recientemente incorporados en su gran mayoría de Europa del Este; afirma que de caras a un nuevo acuerdo global será necesario revisar este principio. Esto se aplica fundamentalmente a China y otros Estados del BASIC. De hecho, lo ha puesto

\footnotetext{
50 PÉREZ DE LAS HERAS, B., op. cit., nota 44.

${ }^{51}$ Conformado por Australia, Canadá, Islandia, Japón, Nueva Zelanda, Noruega, Rusia, Ucrania y Estados Unidos.

52 Conformado por México, Liechtenstein, Mónaco, República de Corea y Suiza.

${ }^{53}$ Como pudo verse en las recientes negociaciones realizadas en la COP19 en Varsovia y fundamentalmente en la reunión de ADP celebrada en Bonn en marzo de 2014.
} 
de manifiesto en las recientes conferencias al sostener, junto con Estados Unidos y el resto del Umbrella Group, su lectura generalista del nuevo principio incorporado en Varsovia de «contribuciones nacionales». Incluso la propuesta de un nuevo protocolo que ha presentado la UE hasta la fecha establece como primer parámetro la participación universal en los esfuerzos de mitigación.

Otro elemento de la política climática europea ha sido la vinculación entre clima y energía donde algunos analistas plantean que la segunda ha protagonizado los esfuerzos. Esta alianza que se sella en 2008 perdura hasta la actualidad y ha sido plasmada no sólo en el objetivo 20/20/20 sino en los objetivos climático-energéticos a 2030 y a 2050: alcanzar una economía de bajo carbono que asegure el suministro energético afrontable y competitivo para todos; reducir la importación de energía disminuyendo así la dependencia externa y crear empleo. Del mismo modo y tocando su incidencia externa, la UE se propuso: reducir las emisiones de GEIs al menor costo posible y en tiempo para cumplir los compromisos internacionales. En tal sentido, reiteramos la relevancia y centralidad del ETS. Esta relación entre el clima y energía que para algunos se mueve en el plano de la tensión, ha adquirido creciente importancia en el marco del conflicto internacional desatado en Ucrania y la dependencia europea del gas ruso.

Ahora bien, todos los elementos mencionados cooperan sinérgicamente para calificar a la UE como Potencia Climática Moral desde la suscripción del CMNUCC hasta 2009. Ese calificativo proviene de su búsqueda de adelantarse a los compromisos internacionales, guiar el proceso de negociación mediante el ejemplo doméstico, ser un actor clave en términos de financiamiento de actividades de reducción en países en desarrollo y ocupar un espacio de ausencia de otras potencias emisoras en el régimen climático internacional. En tal sentido, y en cuanto al rol de la UE en los foros climáticos globales, es posible afirmar que una de las características más notorias radica en suplir el rol de Estados Unidos como líder global y potencia emisora.

Europa ha oscilado en su posición en la lista de potencias emisoras. En 2008 los datos de las agencias de Naciones Unidas certifican que la UE27 emitía 4.177.817 de toneladas de dióxido de carbono anuales, luego de China con más de siete mil millones y Estados Unidos con casi cinco mil quinientos millones de toneladas. Esto implica que al inicio del 1PC, las tres potencias generaban el $56 \%$ de las emisiones globales de dióxido de carbono, como principal GEI. Puesto que Europa ha reducido sus emisiones, este puesto se ha visto modificado, pero aún Alemania, Gran Bretaña, Francia e Italia reúnen en sí mismos casi dos mil millones de toneladas de emisiones de dióxido de carbono para 2011. Para el mismo año, las emisio- 
nes totales de carbono de la UE27 fueron de cuatro mil millones y medio de toneladas ${ }^{54}$.

Además de su capacidad de emisión, y como resultado de la renuencia de Estados Unidos a asumir compromisos obligatorios de reducción en Kyoto, Europa se volvió la locomotora del régimen climático global. Sin embargo, este rol fue cuestionado en Copenhague por las potencias emergentes del BASIC - Brasil, India, China y Sudáfrica - quienes junto con Estados Unidos negociaron un acuerdo final que no tuvo unanimidad entre los Estados pero fue el de mayor consenso. Esta transformación en la estructura del Sistema internacional, que movilizó actores previamente rezagados en el mundo en desarrollo, condicionó la continuidad de las estrategias europeas, no sólo climáticas sino en diversos otros aspectos. Tal es así, que podríamos afirmar que el liderazgo climático relativamente incuestionado europeo se extiende hasta 2009.

Forma parte esencial de ese cambio en la estructura y dinámica del Sistema Internacional la llegada de Barack Obama a la presidencia de los Estados Unidos en 2009. Obama hizo del cambio climático uno de los pilares de su campaña electoral de 2008 junto con el denominado Obamacare, y si bien decidió abandonar el primero a favor del segundo, no hay dudas de que ha mostrado un discurso y un conjunto de acciones que lo distancian de su antecesor en el despacho oval. Algunas muestras de su búsqueda de reinsertar a los Estados Unidos en el régimen climático internacional son la presentación de la Clean Air Act, aunque haya quedado trabado en el Senado norteamericano desde 2010; los compromisos de reducir un $80 \%$ las emisiones norteamericanas e incrementar la participación de energías renovables en un 25\% para 2050; tanto como la búsqueda de generar un sistema de comercio de carbono. Tal como asumen Kelly Ferreira, Solange Reis Ferreira y Tullo Vigevani ${ }^{55}$, Obama interpretó la crisis económica y financiera como una oportunidad en términos de revolución verde. Otro elemento que muestra el giro en la óptica de la administración fue la propia participación de Obama en la COP15 en Copenhague en conjunto con los presidentes del BASIC.

Justamente en tal sentido, la aparición y relevancia que ha adquirido el BASIC en el escenario climático internacional es prueba de las transformaciones a las que hacemos referencia. Copenhague se volvió una bisagra climática en términos del protagonismo de las denomina-

54 European Environment Agency, Annual European Union greenhouse gas inventory 1990-2011 and inventory report 2013, op. cit., nota 8.

55 REIS FERREIRA, S., FERREIRA, K., VIGEVANI, T., «An overview of domestic aspects in us climate policy. Uma visão geral dos aspectos domésticos da política Climática dos EUA», en RBPI, n. ${ }^{\circ}$ 55, 2012, pp. 88-103. 
das potencias medias nucleadas en BASIC. «Algunos de los aspectos que convalidan esta afirmación son: la aceptación a adoptar compromisos voluntarios en materia de reducción de emisiones y concentración energética; el protagonismo de estos actores en detrimento de otros como Estados Unidos o los países de Europa; y finalmente el malestar del G77 por la autoexclusión de éstos y su consolidación como líderes climáticos» ${ }^{56}$. Estas afirmaciones se ven fundamentadas a su vez en un ejercicio de contraste entre las declaraciones y comunicados de los ministros del BASIC y los documentos nacidos en las reuniones COP. Desde nuestra perspectiva, «su poder de influencia ha crecido en menoscabo de las potencias tradicionales como Estados Unidos - que ha continuado reticente en materia de compromisos obligatorios de reducción - y de Europa, como histórico baluarte de los regímenes climáticos. A favor de nuestro argumento aportan: la participación activa de los cuatro países en las COP; su condicionamiento del contenido de los documentos finales; el hecho de que los desacuerdos internos no los han resquebrajado como grupo; que han podido hacer frente común en caso de sentirse amenazados externamente como ocurrió con las medidas unilaterales de la UE; que han comprendido que su construcción de poder debe realizarse - al menos simbólicamente- dentro del G77 + China» ${ }^{57}$.

$\mathrm{Si}$ bien la UE sigue siendo un actor relevante de la arena internacional y un pilar del régimen climático global, a partir de la COP15 ha compartido su liderazgo. Las condiciones de dicho reparto de influencia y de poder están dadas hasta mediados de 2014 por el creciente rol de Estados Unidos y del BASIC puesto de manifiesto. No obstante, sigue abierto el desenlace en lo relativo a las negociaciones en vías a obtener un nuevo acuerdo, protocolo, o documento vinculante que se suscriba en la COP21 en Paris y se abra a la ratificación hasta 2020 .

Las condiciones que expone la UE para dar curso al documento post 2020 comienzan por la proposición de que se trate de un nuevo protocolo a la CMNUCC, cuyo objetivo principal sea que la humanidad no traspase la frontera de incremento de $2{ }^{\circ} \mathrm{C}$. El punto neurálgico es que todas las partes de la Convención participen en los compromisos de mitigación, lo cual choca con la posición del BASIC y del G77+China. Asimismo, propone que sea un documento flexible, dinámico y robusto donde puede leerse una insinuación del sistema bottom-up que es la base de la propuesta de Estados Unidos y del Umbrella Group. Estados Unidos asume que no logrará

56 BUENO, M., «Las potencias medias en la arquitectura climática global: la hibridación de la brecha norte-sur», en Austral: Revista Brasileira de Estratégia e Relações Internacionais, v.2, n. 4, Jul-Dez 2013, p. 215.

57 Ibid., p. 224. 
la ratificación interna de un acuerdo donde dicho Estado se comprometa a una meta de reducción global en un plazo específico - como en PK-. Un acuerdo que en lugar de promover una meta de reducción global fija, como el 5.2\% del PK, responda a un sistema más complejo de metas escalonadas, por país y de acuerdo a las realidades que cada uno de éstos fije, con compromisos individuales de mitigación transparentes, cuantificables, comparables, verificables, ambiciosos y fijados colectivamente que responda al objetivo de $2{ }^{\circ} \mathrm{C}$.

El problema de esta lógica es que derriba uno de los pilares del régimen climático que sostuvo y preservó la UE desde la misma firma de la CMNUCC y su profundización con PK. Esto es, el compromiso de reducción obligatorio y nacional - en PK era de los países desarrollados de acuerdo a CBDR y ahora se pensaría en CBDR y capacidades incorporando a todas las partes - como bastión y garante de que se logre la meta de $2{ }^{\circ} \mathrm{C}$.

\section{Conclusión}

Nos hemos interrogado en esta contribución acerca de cómo construyó la UE su liderazgo climático doméstico y cómo incidieron estas dinámicas en su estrategia de internacionalización de la política climática en los foros globales de 2008 a 2014. Para dar respuesta a la primera parte, tomamos tres grupos de países bien diferenciados que actúan en algunos casos como locomotoras y en otros como ralentizadores de las decisiones climáticas europeas. Estas complejidades que se nutren de posiciones en foros europeos, emisiones, matrices energéticas y otros elementos; condicionan la construcción de la política climática y por ende su capacidad para construir liderazgos externalizables. En tal sentido argumentamos que hasta la COP15 la construcción doméstica del liderazgo europeo, a pesar de ser compleja por los actores intervinientes, logró por un lado disolver las diferencias al interior del bloque y por otro, promover una política climática de liderazgo como Potencia Climática Moral.

La vocación de potenciarse como Potencia Climática Moral se construyó a partir de la interacción de elementos domésticos y externos. Algunos aspectos domésticos fueron enunciados en la segunda parte de esta contribución como el efectivo sinérgico de la relación clima-energía, la estrategia de adelantarse, la conformación de compromisos solidarios de reducción de emisiones y el mercado de carbono. Asimismo y en el plano externo, no asumir compromisos internacionales que no pudieran cumplirse, poner el ejemplo en las políticas climático-energéticas y operar como faro climático global. Es así que la UE se autoimpuso liderar un proceso en ausencia de EEUU y de China que si bien son los principales 
emisores de GEIs, evitaron compromisos globales de reducción durante el 1PC.

Situarse un escalón más arriba del resto, le ha permitido a la UE ejercer presión sobre las otras partes del CMUNCCC alcanzando que el régimen climático global sea, en gran parte, un resultado de sus propias iniciativas domésticas. Sin embargo, a partir de 2010 ese liderazgo se vio cuestionado por la interacción de disensos domésticos más visibles por la crisis en la eurozona; así como por los cambios en el Sistema Internacional, donde el advenimiento de la administración Obama a Estados Unidos y la emergencia de las potencias medias del BASIC, fueron esenciales.

¿Qué significa entonces el atributo de Potencia Climática Moral antes y después de Copenhague? Desde la construcción del régimen climático a principios de la década del noventa hasta 2009, dicho régimen adquirió características de emulación de la política climática doméstica de la UE como su impulsora: los compromisos obligatorios de reducción de emisiones y la introducción de mecanismos de mercado, entre otras condiciones. No obstante, a partir de 2009, la característica de Potencia Climática Moral se volvió más difusa como resultado de: compartir el liderazgo con un presidente norteamericano carismático como es Barack Obama y haber centrado parte de sus campañas electorales entorno a la cuestión climática; el posible «atractivo» de un naciente liderazgo del BASIC, fundamentalmente chino que plantea aún importantes interrogantes en el Sistema Internacional en transición. Si bien gran parte de las condiciones domésticas que convirtieron a Europa en Potencia Climática Moral persisten - no todas puesto que la crisis europea ha calado en sus políticas -, el mundo en el cual se desarrollan a partir de 2009, no es el mismo. El nuevo régimen puede fundarse en un liderazgo compartido de las potencias emergentes lideradas por China con Estados Unidos y la UE, lo cual sería hasta cierto punto deseable si tenemos en cuenta que son los líderes en materia de emisiones.

Ahora bien, a la luz de los últimos documentos presentados por la UE ante la CMNUCC, así como sus discursos en las sesiones de la COP19 en Varsovia y la Conferencia de la Plataforma ADP $^{58}$ en marzo de 2014, pareciera plegarse a las condiciones domésticas norteamericanas para lograr que esta vez Estados Unidos se incorpore efectivamente al régimen. ¿Es esta una forma de evitar el mal mayor que sería que nuevamente Estados Unidos opere como free rider climático? ¿O es más bien una sesión de liderazgo europeo? ¿Es acaso una estrategia de bandwagoning, incorporándose al bando ganador y cediendo el rol de locomotora?

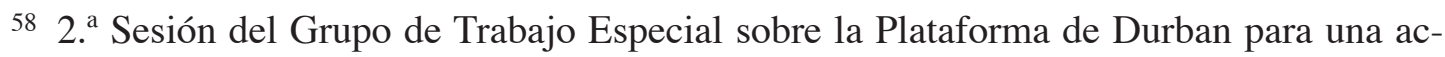
ción reforzada (ADP 2.4), Bonn, marzo de 2014. 
Stephen Walt explica que frente a una amenaza externa, los Estados pueden elegir tanto la estrategia de balancing como de bandwagoning. Define a la primera como una alianza con otros países en contra de una amenaza prevaleciente, mientras que a la segunda como un alineamiento con la fuente de la amenaza ${ }^{59}$. «Balancing es aliarse con el lado más débil, mientras que bandwagoning es hacerlo con el más fuerte» ${ }^{60}$. Walt explica cómo Gran Bretaña ha aplicado la estrategia de balancear, es decir, aliarse con los más débiles a lo largo de 400 años; tanto como Henry Kissinger lo hizo en su armado del triángulo estratégico con China. Sin embargo, deja constancia de que aliarse con el débil permite al aliado pensar en una mayor influencia en su nueva alianza, siendo que al elegir el bando más fuerte - bandwagoning - la influencia es menor y se tiene más posibilidades de ser dominado por el Estado que opera como locomotora.

Con lo cual, las condiciones por las cuales una potencia como la UE decide subirse a la locomotora de otra potencia como los Estados Unidos en su nueva estrategia climática global, quizás se deban a la necesidad de compartir los costos de dicho liderazgo en esta nueva etapa. Creemos que la UE elige la estrategia de bandwagoning porque su poder relativo disminuyó y la fortaleza doméstica que la sostenía como Potencia Climática Moral se ha visto permeada por dificultades específicas como la crisis del euro, fundamentalmente en algunos países como la Península Ibérica, la crisis en Ucrania y el contrapeso que suponen los países del Este, entre otros. Con lo cual, las fuertes transformaciones que experimenta la Unión internamente, la han vuelto vulnerable y por ende, elige compartir su liderazgo aunque esto pueda significar que el nuevo régimen climático global se vea empobrecido en relación a las necesidades pronosticadas por el IPCC.

59 WALT, S., The Origins of Alliances, Cornell University Press, Ithaca, New York, 1987, p. 110.

${ }^{60}$ Ibid., p. 112. 